\title{
Investigation of SNPs in FABP3 and FABP4 Genes and Their Possible Relationships with Fatty Acid Composition in Broiler
}

\author{
Dyah Maharani ${ }^{1}$, Hee Bok Park ${ }^{2,3}$, Yeonkook Jung ${ }^{1}$, Samooel Jung ${ }^{1}$, Cheorun $\mathrm{Jo}^{1}$ and Jun-Heon Lee ${ }^{1,+}$ \\ ${ }^{I}$ Department of Animal Science and Biotechnology, Chungnam National University, Daejeon 305-764, Korea \\ ${ }^{2}$ Division of Applied Life Science, Gyeongsang National University, Jinju 660-701, Korea \\ ${ }^{3}$ Institute of Agriculture and Life Science, Gyeongsang National University, Jinju 660-701, Korea
}

\begin{abstract}
There is limited information of the genetic effect for fatty acid composition in chicken meat. This study assessed the association of FABP3 and FABP4 genes affecting fatty acid composition in broilers. Two single nucleotide polymorphisms (SNPs) were detected in FABP3 gene and five SNPs were identified in FABP4 gene. The SNPs located in intron 1 and exon 1 of FABP3 and FABP4, respectively, were used for genotyping using PCR-RFLP method. The SNPg.285C $>$ T in FABP4 showed suggestive association with high arachidonic acid $(\mathrm{C} 20: 4)$ in CT genotypes $(P=0.068)$. However, the SNP g.508C $>\mathrm{T}$ in FABP3 showed no significant associations with fatty acid composition. These results are the first report to investigate the SNPs in FABP3 and FABP4 genes and their associations with fatty acid composition, although we only found the possible association of FABP4 SNP with fatty acid composition. These results should provide valuable information for further investigation of the genes affecting fatty acid composition in chicken.
\end{abstract}

(Key words : FABP3, FABP4, fatty acid composition, chicken)

\section{INTRODUCTION}

Meat is an important food for human. When people consume meat, they also eat fats in the meat. Therefore the fat composition, especially fatty acids (FAs), is known to be very important for human health. Previously, high intake of saturated FA (SFA) can elevate plasma cholesterol, which contributes to cardiovascular disease (Bronte et al., 1956). SFAs such as lauric acid (C12:0), myristic acid (C14:0), and palmitic acid (C16:0) are considered to have the most harmful cardiovascular effects (Keys et al., 1974). However, high intake of polyunsaturated FA (PUFA) and monounsaturated FA (MUFA) increases hepatic low density lipoprotein (LDL) receptor activity, which leads to the decrease in the circulating concentration of LDL-cholesterol (Woolett et al., 1992). Many consumers consider that red meat is unhealthy because of high SFA and cholesterol levels. Therefore, the replacement of red meat with chicken (white) meat is becoming popular due to consumers' demands for healthy foods. Previous study indicated that diet replacement from red meat to the chicken meat can decrease apolipoprotein B and total cholesterol levels in microal- buminuric (Gross et al., 2002). This may due to the different PUFA contents between chicken meat and red meat (beef). Chicken meat also has a lower portion of saturated and higher PUFA especially in long-chain omega 3 PUFA eicosapentaenoic and docosahexaenoic acids than beef (Almeida et al., 2006). Therefore, fatty acid (FA) composition in chicken meat is very important factor for the consumers' point of view.

The selection of animals having desired phenotypes including desired FA composition can be achieved using molecular techniques including candidate gene approach. One of the strong candidate genes is the FABP gene family. FABPs belong to the member of a superfamily of lipid-binding protein. Based on the tissue-specific distribution, FABPs divided into nine different tissues (Chmurzynska, 2006). Two of them are FAPB3 and FABP4 which also well known as H-FABP and A-FABP, respectively. FABPs act mainly as FA transporters in the metabolic pathway (Estelle et al., 2009), where the peroxisome proliferators-activated receptor (PPAR) family members cooperatively participate as transcription factors. The knock-out mouse study indicated that FAPB3 gene is important for FA transportation and metabolism (Binas et al., 1999).

\footnotetext{
${ }^{\dagger}$ To whom correspondence should be addressed : junheon@cnu.ac.kr
} 
Many studies have been carried out for the association with FABP polymorphisms and fat-related traits in chicken. The FABP4 overexpression adipocytes affect the lipid metabolism through the PPAR $\gamma$ pathway in Arbor Acres chicken (Shi et al., 2010). Markers at the FABP3 and FABP4 genes were associated with IMF content in a population of male Beijing-You chickens (Ye et al., 2010) and in two Chinese chicken breeds Beijingyou and Jingxing (Li et al., 2008). Also, Luo et al. (2007) suggested that the SNP in first exon of FABP4 had effect for the differences among abdominal fat percentage, subcutaneous fat thickness and intramuscular fat contents in breast muscle. However, none of study has been reported in the polymorphisms of FABP gene family and their associated with FA composition in chicken. Therefore, the aim of this study is to identify SNPs in H-FABP and A-FABP genes and their possible associations with fatty acid composition in broiler chicken.

\section{MATERIALS AND METHODS}

\section{Animals and Samples}

Ninety five Ross broilers were used in this study. They were reared under the same feeding conditions until $1.6 \mathrm{~kg}$ of slaughter weight at 28 days age. Tissues from thigh muscle were sampled for genomic DNA isolation and FA composition analysis.

\section{FA Analysis}

Total lipid in each sample was extracted using chloroform-methanol $(2: 1, \mathrm{v} / \mathrm{v})$ according to the procedure of Folch et al. (1957). FA methyl esters were prepared from the extracted lipids with BF3-methanol (Sigma-Aldrich, St. Louis, MO, USA) and separated on a HP-6890N gas chromatograph (Hewlett-Packard, Palo Alto, CA, USA) as described previously (Jeon et al., 2010). A split inlet (split ratio, 50:1) was used to inject samples into a $30 \mathrm{~m} \times 0.25 \mathrm{~mm} \times 0.25 \mu \mathrm{m}$ Omegawax 320 capillary column (Supelco, Bellefonte, PA, USA). The oven temperature regimen consisted of $150^{\circ} \mathrm{C}$ for $3 \mathrm{~min}$, an increase to $180^{\circ} \mathrm{C}$ at $2.5^{\circ} \mathrm{C} / \mathrm{min}, 180^{\circ} \mathrm{C}$ for $5 \mathrm{~min}$, an increase to $220^{\circ} \mathrm{C}$ at $2.5^{\circ} \mathrm{C} / \mathrm{min}$, and $220^{\circ} \mathrm{C}$ for $25 \mathrm{~min}$. The inlet temperature was $210^{\circ} \mathrm{C}$. Air was the carrier gas at a constant flow of $0.7 \mathrm{~mL} / \mathrm{min}$.

\section{DNA Extraction and Genotyping}

Genomic DNAs were extracted from muscle samples and isolated by $20 \mathrm{mg} / \mathrm{mL}$ proteinase $\mathrm{K}$ digestion followed by phenol extraction. Primers and polymerase chain reaction (PCR) information for the FABP3 and FABP4 genes were shown in Table 1. The PCR mixture contained 50 ng genomic DNA, $10 \times$ buffer mix and $10 \mathrm{mM}$ dNTPs (GenetBio, Chungnam, Korea). Amplifications were performed at $10 \mathrm{~min}$ at $94^{\circ} \mathrm{C}, 35$ cycles of $30 \mathrm{~s}$ at $94^{\circ} \mathrm{C}, 30 \mathrm{~s}$ at the annealing temperature, and $30 \mathrm{~s}$ at $72^{\circ} \mathrm{C}$, and a final extension of $10 \mathrm{~min}$ at $72^{\circ} \mathrm{C}$ using either a GeneAmp PCR system 2700 (Applied Biosystems, Franklin Lakes, NJ, USA) or a $\mathrm{C}^{1000^{\mathrm{TM}}}$ Thermal Cycler (BioRad Laboratories, Hercules, CA, USA). The PCR products were visualized in $1.5 \%$ standard agarose gels stained with ethidium bromide (GenetBio). Each PCR fragment was purified using an AccuPrep PCR Purification Kit (Bioneer, Daejeon, Korea). Purified PCR products were sequenced using the same primers for PCR reaction in a model 3730 XL automated DNA Sequencer (Applied Biosystems). The DNA sequences were analyzed with the BioEdit program ver. 7.00 (Tom Hall, Ibis Therapeutics, California, USA) and the single nucleotide polymorphisms (SNPs) were confirmed based on the electrophoregram results. The SNPs in FABP3 and FABP4 genes were genotyped by the PCR-restriction fragment length polymorphism (PCR-RFLP) method (Table 1). The restriction enzyme digestion was performed in $20 \mu \mathrm{L}$ reaction volumes with approximately $15 \mu \mathrm{L}$ of PCR products and 2 units of each restriction enzyme. The digested products were run on $3 \%$ agarose gels.

\section{Statistical Analyses}

The effects of FABP3 and FABP4 genotypes on FA composition traits were tested using the general linear model (GLM) in the SPSS ver. 17.0 program (SPSS, Chicago, IL, USA). In order to test the pair wise differences between the effects of genotype, least significant difference (LSD) test was also performed. Pearson's Chi-square test was used to test the allele and genotype frequency for Hardy-Weinberg equilibrium. The following model was used to test the association of the genotype with FAs composition:

$$
Y_{\mathrm{i}}=\mu+G_{\mathrm{i}}+\varepsilon_{\mathrm{i}}
$$


Table 1. Primers for PCR amplification and SNP identification in FABP3 and FABP4 genes

\begin{tabular}{|c|c|c|c|c|c|}
\hline Gene & $\begin{array}{c}\text { GenBank } \\
\text { accession No. }\end{array}$ & $\begin{array}{l}\text { Sequence } \\
\left(5^{\prime} \text { to } 3 \text { ') }\right.\end{array}$ & $\begin{array}{l}\text { PCR product size } \\
\text { (bp) }\end{array}$ & $\begin{array}{l}\text { Annealing } \\
\text { temperature }\end{array}$ & $\begin{array}{l}\text { Identified SNP } \\
\text { (location) }\end{array}$ \\
\hline \multirow[t]{6}{*}{ FABP3 } & NC_006110 & F3-1: ggtgatgcatgaggacattg & 460 & $58^{\circ} \mathrm{C}$ & g.476G $>$ A (intron 1) \\
\hline & & R3-1: actaccgecttgctcacact & & & g. $508 \mathrm{C}>\mathrm{T}$ (intron 1) \\
\hline & & F3-2: gaatggtggttctgctct & 162 & $58^{\circ} \mathrm{C}$ & No SNP identified \\
\hline & & R3-2:tcccccatctaaaatcct & & & \\
\hline & & F3-3:tgctcacetcetgctctttg & 219 & $58^{\circ} \mathrm{C}$ & No SNP identified \\
\hline & & F3-3:ccatgagaccacagcatcac & & & \\
\hline \multirow[t]{6}{*}{ FABP4 } & NC_006089 & F4-1: tgtgacctactggcaaagga & 477 & $58^{\circ} \mathrm{C}$ & g.184A > G (UTR) \\
\hline & & R4-1: ttcctcccagtcaagctttc & & & g. $285 \mathrm{C}>\mathrm{T}$ (exon 1) \\
\hline & & F4-2: gcaattgccttgtctcatcc & 714 & $58^{\circ} \mathrm{C}$ & g. $1533 \mathrm{C}>\mathrm{T}$ (intron 2) \\
\hline & & R4-2:aactcaccaccagcaggttc & & & g.1965A > G (exon 3) \\
\hline & & F4-3:attggctcccagtgcataag & 361 & $60^{\circ} \mathrm{C}$ & g. $3547 \mathrm{C}>\mathrm{T}$ (intron 4) \\
\hline & & F4-3: caaggcccgttctgactaat & & & \\
\hline
\end{tabular}

Where, $Y$ is the phenotypic data (FA composition) of sample $i, \mu$ is the overall mean, $G$ is the genotype effect of sample $i$ and $\varepsilon$ is a random error.

\section{RESULTS AND DISCUSSION}

\section{FA Composition Profile}

Table 2 shows the descriptive statistics for the FA composition in 95 broiler chicken samples used in this study. Fourteen FAs including total SFA, PUFA and MUFA were measured in each meat sample. The results indicated total SFA was lower than MUFA but higher than PUFA. Total SFA contained four FAs, namely myristic acid (C14:0), palmitic acid (C16:0) stearic acid (C18:0) and arachidic acid (C20:0), with an average level of $0.89 \%, 24.27 \%, 10.47 \%$ and $0.09 \%$, respectively. Total MUFA (C14:1; C16:1; C18:1) and PUFA (C18:2; C18:3; C20:4; C22:6) were calculated by adding each of the three and four FAs, respectively. White meat including chicken meat was considered has lower level of SFA and higher PUFA compared to red meats (Almeida et al., 2006). The high level of PUFA influences the lipid oxidation that affects in meat quality including color, flavor, texture and nutritional value (Tang et al., 2001). The current study also detected the level of total SFA was lower than previous study in beef (Bhuiyan et al., 2009) but higher than pigs (Estelle et al., 2009a). Moreover, these results also indicated having more number of unsaturated FA, which is important to dietary alteration in human that leads to decrease in the circulating concentration of LDL-cholesterol (Woolett et al., 1992). Interestingly, this result detected the rare FA, docosahexaenoic acid (DHA). DHA is essential for infants, especially for growth and functional development of the brain (Horrocks and Yeo, 1999). Plentiful dietary DHA improves learning ability of infants. Dietary and age considered have influencing in the variation of FA composition in broiler (Lopez-Ferrer et al., 2001; Poureslami et al., 2010). Poureslami et al (2010) reported broiler feed with linseed oil and fish oil resulted in increasing C18:2n-6 and C20:4n-6; C22:6n-3, C20:5n-3 and C22:5n-3, respectively. Moreover, the effect of age decreased the level of long-chain n-3 and n-6 PUFA, but gender gave marginal effect to FA composition. This indicates that many factors influence variation of FA composition. 
Table 2. Descriptive statistics for fatty acid composition in 95 broilers used in this study

\begin{tabular}{lrrrr}
\hline \multicolumn{1}{c}{ Traits } & Mean & $\mathrm{SD}^{4}$ & Min & Max \\
\hline Myristic acid (C14:0) & 0.89 & 0.18 & 0.00 & 1.19 \\
Myristoleic acid (C14:1) & 0.19 & 0.07 & 0.04 & 0.34 \\
Palmitic acid (C16:0) & 24.27 & 1.13 & 21.89 & 28.00 \\
Palmitoleic acid (C16:1) & 4.58 & 1.07 & 1.80 & 6.76 \\
Stearic acid (C18:0) & 10.74 & 2.53 & 5.93 & 20.09 \\
Oleic acid (C18:1) & 37.62 & 3.59 & 28.26 & 45.14 \\
Linoleic acid (C18:2) & 16.90 & 1.54 & 13.37 & 20.53 \\
$\alpha \quad$ Linolenic acid (C18:3) & 0.64 & 0.15 & 0.28 & 1.00 \\
Arachidic acid (C20:0) & 0.09 & 0.03 & 0.05 & 0.20 \\
Arachidonic acid (C20:4) & 3.49 & 1.33 & 1.05 & 6.37 \\
Docosahexaenoic acid (C22:6) & 0.54 & 0.21 & 0.14 & 1.06 \\
SFA $^{1}$ & 36.00 & 3.07 & 30.00 & 47.22 \\
MUFA $^{2}$ & 42.41 & 4.46 & 30.10 & 50.66 \\
PUFA $^{3}$ & 21.59 & 2.72 & 15.91 & 28.52 \\
\hline
\end{tabular}

The superscripts 1, 2, 3 denote total saturated fatty acid (SFA), monounsaturated fatty acid (MUFA) and polyunsaturated fatty acid (PUFA), respectively. ${ }^{4} \mathrm{SD}$ is standard deviation of percentage FA composition.

\section{Genotyping and Allele Frequency}

SNPs were initially identified by direct sequencing of the FABP3 and FABP4 genes using fifteen chicken DNA samples. As the results, two SNPs of FABP3 and five SNPs of FABP4 were identified. Among these, the SNP g.508C $>$ T in FABP3 located in intron 1 and The SNP g.285C $>\mathrm{T}$ in FAPB4 located in exon 1 can use for the genotyping using PCR-RFLP. Initially, the $460 \mathrm{bp}$ PCR product of FABP3 was digested using NlaIII restriction enzyme. Four fragments, 201, 176, 72 and $11 \mathrm{bp}$, were identified in animals having the $\mathrm{CC}$ genotype, and five fragments, 201, 140, 72, 36 and $11 \mathrm{bp}$, were identified in TT genotype (Fig. 2). It should be noted that the small fragments (less than $100 \mathrm{bp}$ ) were not distinguishable in the gel pictures. Similarly, FABP4 PCR product (477 bp) was digested into 235 and 242 bp in CC genotype, but undigested results were observed in animals having TT genotype (477 bp) using TagI restriction enzyme (Fig. 2). The geno
(A) FABP3
SNP 1 C-3_C-FABP3-P1B-R_C07.ab1

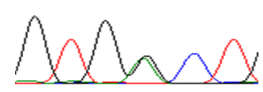
g. $476 \mathrm{G}>\mathrm{A}$ $\mathrm{G} \quad \mathrm{T} G \mathrm{~N} \quad \mathrm{C} \stackrel{1020}{\mathrm{~T}}$
SNP 2 -KC-3_C-FABP3-P1B-R_C07.ab C C A ${ }_{\mathrm{N}}^{1050} \mathrm{G}$

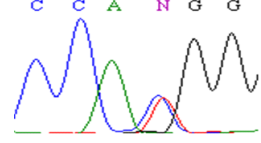
g.508C > T
(B) FABP4
SNP 1

0_P1-1_CFABP4-P1-F_E08:A

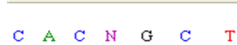

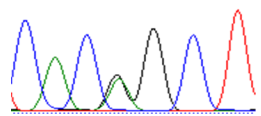

g. $184 \mathrm{~A}>\mathrm{G}$

SNP 4

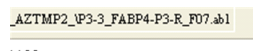

$1190 \quad \mathrm{C} \quad \mathrm{A} \quad \mathrm{N} \quad \mathrm{T} \quad \mathrm{G}$

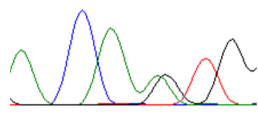

g. $1965 \mathrm{~A}>\mathrm{G}$
SNP 2 TMPO_PP1-1_CFABP4-P1-F_E08.ab] AP2_[P3-3_FABP4-P3-R_R07

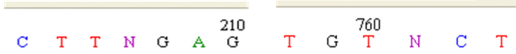

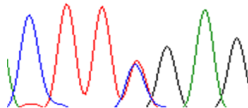
g. $285 \mathrm{C}>\mathrm{T}$

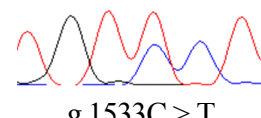

Fig. 1. Electrophoregram results for the identified SNPs in FABP3 (A) and FABP4 (B) genes.
(A)

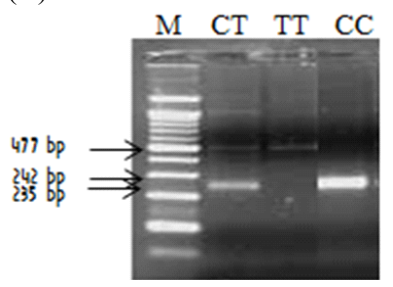

(B)

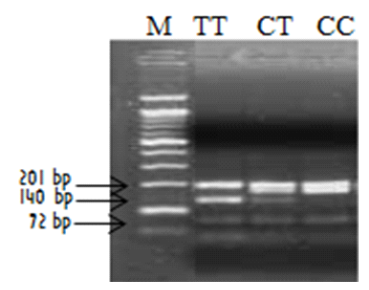

Fig. 2. PCR-RFLP patterns of g.508C $>$ T SNP (digested with NlaIII) in FABP3 gene (A) and g.285C $>$ T SNP (digested with TaqI) in FABP4 (B).

type frequency of both of genes was shown in Table 3. Pearson's Chi-square test was used to test the Hardy-Weinberg equilibrium and the genotypes of FABP3 and FABP4 genes were deviated from Hardy-Weinberg equilibrium (HWE). The deviation from HWE may be due to a variety of causes. Mutation, gene flow, non-random mating (assortative mating), genetic drift and selection are possible factors that may lead to deviate from HWE (Falconer and Mackay, 1996). In a case of this study, we can postulate non-random mating and small 
Table 3. The effect of SNPs in FABP3 and FABP4 genes with fatty acid composition in broilers (mean $\pm \mathrm{SE}$ )

\begin{tabular}{|c|c|c|c|c|c|c|}
\hline \multirow{3}{*}{ Trait } & \multicolumn{3}{|c|}{ FABP3 } & \multicolumn{3}{|c|}{ FABP4 } \\
\hline & \multicolumn{3}{|c|}{ g. $508 \mathrm{C}>\mathrm{T}$} & \multicolumn{3}{|c|}{ g. $285 \mathrm{C}>\mathrm{T}$} \\
\hline & $\begin{array}{c}\mathrm{CC} \\
(0.33)^{\mathrm{a}}\end{array}$ & $\begin{array}{c}\text { CT } \\
(0.55)\end{array}$ & $\begin{array}{c}\text { TT } \\
(0.12)\end{array}$ & $\begin{array}{c}\mathrm{CC} \\
(0.27)\end{array}$ & $\begin{array}{c}\text { CT } \\
(0.60)\end{array}$ & $\begin{array}{c}\text { TT } \\
(0.13)\end{array}$ \\
\hline Myristic acid (C14:0) & $0.88 \pm 0.03$ & $0.91 \pm 0.03$ & $0.89 \pm 0.05$ & $0.93 \pm 0.04$ & $0.88 \pm 0.02$ & $0.94 \pm 0.05$ \\
\hline Myristoleic acid (C14:1) & $0.20 \pm 0.01$ & $0.19 \pm 0.01$ & $0.19 \pm 0.02$ & $0.20 \pm 0.01$ & $0.19 \pm 0.01$ & $0.21 \pm 0.02$ \\
\hline Palmitic acid (C16:0) & $24.22 \pm 0.20$ & $24.40 \pm 0.16$ & $23.78 \pm 0.34$ & $24.50 \pm 0.22$ & $24.20 \pm 0.15$ & $24.13 \pm 0.33$ \\
\hline Palmitoleic acid (C16:1) & $4.58 \pm 0.19$ & $4.54 \pm 0.15$ & $4.71 \pm 0.33$ & $4.67 \pm 0.21$ & $4.50 \pm 0.14$ & $4.84 \pm 0.31$ \\
\hline Stearic acid (C18:0) & $10.68 \pm 0.46$ & $10.92 \pm 0.35$ & $10.38 \pm 0.77$ & $10.70 \pm 0.50$ & $10.86 \pm 0.34$ & $10.28 \pm 0.74$ \\
\hline Oleic acid (C18:1) & $37.94 \pm 0.64$ & $37.08 \pm 0.49$ & $38.81 \pm 1.07$ & $37.19 \pm 0.70$ & $37.45 \pm 0.47$ & $39.38 \pm 1.03$ \\
\hline Linoleic acid (C18:2) & $16.77 \pm 0.28$ & $17.05 \pm 0.22$ & $16.69 \pm 0.47$ & $16.94 \pm 0.30$ & $17.00 \pm 0.20$ & $16.35 \pm 0.45$ \\
\hline$\alpha$ Linolenic acid (C18:3) & $0.64 \pm 0.03$ & $0.64 \pm 0.02$ & $0.63 \pm 0.05$ & $0.65 \pm 0.03$ & $0.63 \pm 0.02$ & $0.68 \pm 0.04$ \\
\hline Arachidic acid (C20:0) & $0.09 \pm 0.005$ & $0.10 \pm 0.004$ & $0.08 \pm 0.009$ & $0.10 \pm 0.01$ & $0.09 \pm 0.004$ & $0.10 \pm 0.009$ \\
\hline Arachidonic acid (C20:4) & $3.45 \pm 0.24$ & $3.61 \pm 0.18$ & $3.31 \pm 0.40$ & $3.56 \pm 0.26$ & $3.64 \pm 0.17$ & $2.67 \pm 0.38$ \\
\hline Docosahexaenoic acid (C22:6) & $0.51 \pm 0.04$ & $0.56 \pm 0.03$ & $0.54 \pm 0.06$ & $0.56 \pm 0.41$ & $0.55 \pm 0.03$ & $0.43 \pm 0.31$ \\
\hline $\mathrm{SFA}^{1}$ & $35.87 \pm 0.55$ & $36.33 \pm 0.43$ & $35.13 \pm 0.93$ & $36.45 \pm 0.61$ & $36.03 \pm 0.41$ & $35.45 \pm 0.89$ \\
\hline MUFA $^{2}$ & $42.72 \pm 0.80$ & $41.81 \pm 0.61$ & $43.71 \pm 1.34$ & $42.07 \pm 0.87$ & $42.13 \pm 0.59$ & $44.42 \pm 1.28$ \\
\hline PUFA $^{3}$ & $21.38 \pm 0.50$ & $21.86 \pm 0.38$ & $21.16 \pm 0.82$ & $21.71 \pm 0.53$ & $21.82 \pm 0.36$ & $20.13 \pm 0.78$ \\
\hline
\end{tabular}

${ }^{\mathrm{a}}$ Genotype frequency.

${ }^{1-3}$ Total SFA: Saturated fatty acid; Total MUFA: Monounsaturated fatty acid; Total PUFA: Polyunsaturated fatty acid.

population size may influence this deviation.

\section{Effects of SNP Genotypes with FA Compo- sition}

The general linear model was used to analyze the association of polymorphisms in two FABP family genes with FA compositions (Table 3). The LSD test was carried out to investigate the comparisons of the means of each FA composition among genotypes. The investigation of the genotype effects revealed g.285C $>\mathrm{T}$ polymorphisms in exon 1 of FABP4 shown have no associated with FA composition. Similarly, the SNP identified in FABP3 had not demonstrated any interaction with FA composition.

In this study, ninety five broilers were genotyped using the SNPs in the FABP3 and FABP4 genes. The objective of this study was to evaluate whether there is potential genetic association between the SNP markers in both genes and FA com- position. There is a causal reason for the hypothesis because FABP genes encoding the protein that are involved in FA transfer to acceptor membranes by direct interaction with the phospholipid bilayer or by an aqueous diffusion-mediated process (Hsu and Storch, 1996). Another study supported that the overexpression of FABP plasma membrane group in mammalian tissues can increase FA transport (Clarke et al., 2004). They reported, in mammalian, FABP plasma membrane overexpression increased the rates of palmitate transport across the sarcolemma, an effect that was independent of any changes in FAT/CD36. In the present study, a novel g.285C $>$ T SNP in the third exon of the chicken FABP4 gene has been detected and shown the concentration of arachidonic acid (C20: 4) increased to $3.64 \%$ in heterozygote genotype $(P<0.05)$ and decreased to $2.6 \%$ in TT genotype compare to CT genotype $(P<0.021)$ even though overall effect of those genotypes did not significant $(P=0.068)$. Therefore, there is limi- 
tation in determining the association of the SNP with arachidonic acid (C20:4) confidently. Similarily, docosahexaenoic acid (C22:6; $P=0.068)$ and PUFA $(P=0.051)$ have suggestive associations. Moreover, the results of GLM analysis indicated the SNP g.508C $>\mathrm{T}$ in FABP3 had no association in all of FA composition traits.

\section{CONCLUSION}

In this study, two SNPs in FABP3 and five SNPs in FABP4 genes were identified in broilers and their possible associations with fatty acid composition in thigh muscle tissue were investigated. Even though there were no association between the SNPs in both FABP3 and FABP4 with FA composition, the suggestive significant results for FABP4 and arachidonic acid (C20:4) have been identified in this study. The results presented here can provide valuable information for further investigation of the genes affecting fatty acid composition in chicken.

\section{ACKNOWLEDGEMENTS}

This work was supported by a grant from the Next-Generation BioGreen 21 Program (Project Number: PJ008133). Rural Development Administration, Republic of Korea.

\section{LITERATURE CITED}

Almeida JCd, Perassolo MS, Camargo JL, Bragagnolo N, Gross JL 2006 Fatty acid composition and cholesterol content of beef and chicken meat in Southern Brazil. Brazilian Journal of Pharmaceutical Sciences 42:109-117.

Bhuiyan MSA, Yu SL, Jeon JT, Yoon D, Cho YM, Park EW, Kim EW, Kim KS, Lee JH 2009 DNA polymorphisms in SREBF1 and FASN genes affect fatty acid composition in Korean cattle (Hanwoo). Asian-Aust J Anim Sci 22:765773.

Binas B, Danneberg H, McWhir J, Mullins L, Clark AJ 1999 Requirement for the heart type fatty acid binding protein in cardiac fatty acid binding protein utilization. Fasep J 13: $805-812$.

Bronte SB, Antonis A, Eales L, Brock JF 1956 Effects of fee- ding different fats on serum-cholesterol level. The Lancet 270:521-526.

Chmurzynska A 2006 The multigene family of fatty acid-binding proteins (FABPs): function, structure and polymorphism. J Appl Genet 47:39-48.

Clarke DC, Miskovic D, Han X-X, Calles-Escandon J, Glatz JFC, Luiken JJFP 2004 Overexpression associated fatty acid binding protein (FABPpm) in vivo increases fatty acid sarcolemmal transport and metabolism. Physiol Genomics $17: 31-37$.

Estelle J, Mercade A, Perez-Enciso M, Pena RN, Silio L, Sanchez A, Folch JM 2009 Evaluation of FABP2 as candidate gene for a fatty acid composition QTL in porcine chromosome 8. J Anim Breed Genet 126:52-58.

Falconer DS, Mackay TFC 1996 Hardy-Weinberg Equilibrium. pp 5-18. In: Introduction to Quantitative Genetics, $4^{\text {th }}$ edition. Addison Wesley Longman, Harlow, Essex, UK

Folch J, Lees M, Stanley GHS 1957 A simple method for the isolation and purification of total lipides from animal tissues. J Biol Chem 226:497-509.

Gross JL, Zelmanovitz T, Moulin CC, De-Mello V, Perassolo M, Leitao C, Hoefel A, Paggi A, Azevedo MJ 2002 Effect of a chicken based diet on renal function and lipid profile in patients with type 2 diabetes. D Care 25:645-651.

Horrocks LA, Yeo YK 1999 Health benefits of docosahexaenoic acid (DHA). Pharmacol Res 40:211-225.

Hsu KT, Storch J 1996 Fatty acid transfer from liver and intestinal fatty acid-binding proteins to membranes occurs by different mechanisms. J Biol Chem 271:13317-13323.

Jeon HJ, Choe JH, Jung Y, Kruk ZA, Lim DG, Jo C 2010 Comparison of the chemical composition, textural characteristics, and sensory properties of north and south Korean native chickens and commercial broilers. Korean J Food Sci Anim Resour 30:171-178.

Keys A, Grande F, Anderson JT 1974 Bias and misrepresentation revisited: Perspective in saturated fat. Am J Clin Nutr 27:188-212.

Li WJ, Li HB, Chen JL, Zhao GP, Zheng MQ, Wen J 2008 Gene expression of heart- and adipocyte-fatty acid-binding protein and correlation with intramuscular fat in Chinese chickens. Anim Biotechnol 19:189-193.

Lopez-Ferrer S, Baucells MD, Barroeta AC, Galobart J, Gra- 
shorn MA 2001 n-3 enrichment of chicken meat. 2. Use of precursors of long-chain polyunsaturated fatty acids: linseed oil. Poultry Sci 80:753-761.

Luo GF, Chen JL, Wen J, Zhao GP, Zheng MQ, Sun SD 2006 Study of single nucleotide polymorphism of A-FABP gene and its association with fatness traits in chicken. Yi Chuan 28:39-42.

Poureslami R, Raes K, Huyghebaert G, De Smet S 2010 Effects of diet, age and gender on the polyunsaturated fatty acid composition of broiler anatomical compartments. Br Poult Sci 51:81-91.

Shi H, Wang Q, Wang Y, Leng L, Zhang Q, Shang Z, Li H 2010 Adipocyte fatty acid-binding protein: An important gene related to lipid metabolism in chicken adipocytes. Comp Biochem Physiol B Biochem Mol Biol 157:
357-363.

Tang S, Kerry JP, Sheehan D, Buckley DJ 2001 A comparative study of tea catechins and $\alpha$-tocopherol as antioxidants in cooked beef and chicken meat. European Food Research and Technology 213:286-289.

Woolett LA, Spady DK, Dietchy JM 1992 Saturated and unsaturated fatty acid independently regulate low density lipoprotein receptor activity and production rate. J Lipid Res 33:77-88.

Ye MH, Chen JL, Zhao GP, Zheng MQ, Wen J 2010 Associations of A-FABP and H-FABP markers with the content of intramuscular fat in Beijing-You chicken. Anim Biotechnol 21:14-24.

(접수: 2011. 8. 17, 수정: 2011. 9. 8, 채택: 2011. 9. 9) 